\title{
Horizons/Théâtre
}

Revue d'études théâtrales

\section{Le théâtre de l'Afrique francophone noire et la théorie postcoloniale : cas du théâtre camerounais des années soixante aux années quatre-vingt}

Guy Francis Tami Yoba

\section{(2) OpenEdition}

Journals

Édition électronique

URL : https://journals.openedition.org/ht/1112

DOI : $10.4000 /$ ht. 1112

ISSN : 2678-5420

Éditeur

Presses universitaires de Bordeaux

Édition imprimée

Date de publication : 31 décembre 2018

Pagination : 96-106

ISBN : 979-10-300-0318-5

ISSN : 2261-4591

Référence électronique

Guy Francis Tami Yoba, « Le théâtre de l'Afrique francophone noire et la théorie postcoloniale : cas du théâtre camerounais des années soixante aux années quatre-vingt », Horizons/Théâtre [En ligne], 13| 2018, mis en ligne le 01 janvier 2019, consulté le 17 mai 2022. URL : http://journals.openedition.org/ ht/1112 ; DOI : https://doi.org/10.4000/ht.1112

\section{c) $(1) \Theta$}

La revue Horizons/Théâtre est mise à disposition selon les termes de la Licence Creative Commons Attribution - Pas d'Utilisation Commerciale - Pas de Modification 4.0 International. 


\section{GUY FRANCIS TAMI YOBA}

Guy Francis Tami Yoba est chargé de cours, et enseignant-chercheur en Arts du spectacle et Cinématographie au département des Arts et Archéologie à I'Université de Yaoundé I, Cameroun. La Production théâtrale est sa spécialisation. Il opère comme comédien et metteur en scène depuis une vingtaine $d^{\prime}$ 'années. Parmi ses dernières publications : "Tendances actuelles de la mise en scène dans les pratiques théâtrales contemporaines camerounaise et roumaine » (Revue Mélanges francophones, vol. X, n० 13/2016) et « Innovation festivalière et renforcement des industries dramatiques au Cameroun : le cas des Rencontres Théâtrales Universitaires (RETU) » (in actes du colloque des DJSL, 2014).

Mail: aahomo77@yahoo.fr

Résumé : Le Cameroun, tout comme les autres pays de l'Afrique francophone noire, a été marqué durablement par le fer de la colonisation. Aussi, dès l'accession aux indépendances (1960), dans le but d'exorciser le spectre du mal laissé par les colons, et de jeter les jalons en vue de l'édification d'une nouvelle société, les dramaturges de la première heure vont développer une forme d'écriture théâtrale essentiellement orientée sur la recherche de l'esthétique identitaire. Dans le cadre du présent article, il est question de s'appuyer sur la théorie postcoloniale pour démontrer que les créa-

Abstract : Cameroon, like the other countries of black French-speaking Africa, has been permanently marked by the iron of colonization. Also, upon gaining independence (1960), in order to exorcise the specter of evil left by the colonists, and to lay the groundwork for the construction of a new society, the dramatists of the first hour will develop a form of theatrical writing essentially oriented towards the search for identity aesthetics. In the context of this article, it is a question of relying on postcolonial theory to demonstrate that the dramatic creations of tions dramatiques de l'Afrique francophone noire postindépendance sont de véritables espaces de résistance, de lutte et de reconquête de libertés individuelles et collectives. Pour se faire, la période postindépendance nous servant de seul point focal, cette étude nécessite un regard Historique préalable à l'approche Analytique, enfin il sera fait appel à la théorie de la Réception des spectacles.

Mots-cLés : théâtre, Afrique francophone noire, colonisation, indépendance, esthétique identitaire, résistance.

post-independence black French-speaking Africa are real spaces of resistance, struggle and the reconquest of individual and collective freedoms. To do this, the post-independence period serving as our only focal point, this study requires a Historical look prior to the Analytical approach; finally it will be called upon the theory of Reception of shows.

KEYworDs: Theater, Black French-speaking Africa, Colonization, Independence, Identity aesthetics, Resistance. 


\section{Le théâtre de l'Afrique francophone noire et la théorie postcoloniale : cas du théâtre camerounais des années soixante aux années quatre-vingt}

\section{Introduction}

APRÈS PRÈS D'UN SIÈCLE D'ASSERVISSEMENT, de traumatisme, de conditionnement et de reprogrammation des mentalités, de stigmatisation de la culture de l'homme noir, de diffusion d'une vision dichotomique de ce dernier, et de bien d'autres ravages causés par la colonisation ${ }^{1}$ (1884-1959), le Cameroun, tout comme la plupart des pays de l'Afrique francophone noire, accède enfin à l'indépendance en 1960. Étaux lendemains des indépendances, il est surtout question de réédifier une nouvelle société. Car ce qui tenait lieu de socle social avait été lourdement fragilisé par l'idéologie du colon. Ainsi, les compatriotes de l'époque, animés par la recherche d'un nouveau commencement, vont s'engager dans un vaste chantier de reconstruction sociale. Cependant, le Cameroun, qui a été durablement marqué par le fer de la colonisation, arrive déboussolé aux indépendances, pour ne pas dire sans repères. Aussi, conscients de l'importance de leur rôle dans ce vaste chantier de reconstruction sociale, les dramaturges camerounais de la première heure vont proposer, à travers leurs créations dramatiques, de jeter les jalons devant servir de fondation et de frontispice à la reconstruction sociale. Ce faisant, ils vont se lancer dans une création dramatique exclusivement orientée vers la recherche de l'esthétique identitaire. Ainsi, dans le présent article, il est question de s'appuyer sur la théorie postcoloniale pour démontrer que les créations dramatiques de l'Afrique francophone noire postindépendance, en l'occurrence celles du Cameroun, sont de véritables espaces de résistance, de lutte et de reconquête de l'identité culturelle, et partant des libertés individuelle et collective. Et dans cette même logique on cherchera à savoir quel a été l'impact réel et les retombées de cette forme de théâtre dans l'imaginaire populaire camerounais. 


\section{Cadre théorique et méthodologie}

Pour ce faire, la période postindépendance nous servant de seul point focal, notre démarche conceptuelle se compose de trois théories.

Pour mieux saisir la notion de la théorie postcoloniale prônée dans les créations dramatiques postindépendances, il convient d'abord de jeter un regard historique préalable à une approche critique-analytique sur les ravages de la colonisation au Cameroun. Pour ce faire, l'ouvrage Cameroun : Histoire d'un nationalisme 1884-1961 de Daniel Abwa servira de socle. Ensuite, à la faveur de l'ouvrage L'esthétique de la Réception de Jauss Hans Robert ${ }^{2}$, nous nous appuierons sur les traits caractéristiques de deux œuvres majeures pour mettre en lumière le concept de la recherche de l'esthétique identitaire, d'une part, et d'autre part, apprécier l'impact dudit concept dans l'imagerie populaire camerounaise. Et l'instrument retenu pour la collecte des données est essentiellement la recherche documentaire.

\section{Bref regard historique et critique sur les ravages de la colonisation au Cameroun}

\section{Aux racines de l'acte colonial}

C'est à Berlin le 15 novembre 1884 que naît l'acte colonial. En effet, « la conférence de Berlin marqua l'organisation et la collaboration européenne pour le partage et la division de l'Afrique. Aussi connue comme la conférence de l'Afrique de l'Ouest, elle commença le 15 novembre 1884 à Berlin et finit le 26 février $1885^{3} \gg$. Poussées par leurs ambitions impérialistes, certaines puissances européennes, d'un commun accord, décident du sort de tout un continent. Pour mieux arbitrer la ruée sur l'objet du désir et de toutes les convoitises (l'Afrique), les colonisateurs vont se partager le continent africain comme un gâteau. Plus encore, ils vont penser et mettre sur pied un traité (ensemble de règles) que tous les membres de la conférence de Berlin se devront de respecter. Et dans le but de justifier leur action, mieux encore leur idéologie, aux yeux du monde entier, les colonisateurs s'appuieront sur les arguments de Kipling ${ }^{4}$. Ainsi, la «mission civilisatrice $\gg$ dont les colons se sentent investis est le prétexte brandi pour justifier l'action coloniale.

Pour ce faire, les colonisateurs vont procéder par étapes. Tout commence par des conquêtes fulgurantes, sanglantes et meurtrières. Ensuite arrivent les forces d'occupation que sont les missionnaires qui sont chargés du balisage du chemin. Et pour soutenir l'action de ces derniers, et donner un visage plus officiel à l'action coloniale, la puissance colonisatrice envoyait des régents ou 
Le théâtre de l'Afrique francophone noire et la théorie postcoloniale : cas du théâtre camerounais des années soixante aux années quatre-vingt

gouverneurs pour gérer (direct rule) $)^{5}$ ou administrer (indrectrule) $)^{6}$ la colonie selon les idéologies de la métropole.

Quelle que soit la forme de l'administration appliquée sur le terrain par les colons, les actes posés au fil du temps par ces derniers témoigneront à suffisance que derrière la belle façade de la mission civilisatrice prônée par les colonisateurs se cachent des intentions malveillantes aux effets destructeurs.

\section{Les ravages de la colonisation}

Pour atteindre leurs objectifs escomptés, les colonisateurs vont utiliser la religion chrétienne. Et le théâtre sera choisi comme instrument de propagande et d'asservissement pour véhiculer l'idéologie du colon. C'est la naissance du théâtre colonial ${ }^{7}$. Cette forme d'expression artistique, qui se pratique sous l'égide des missionnaires ou dramaturges à la soutane, naît dès le début de la colonisation, et se manifeste essentiellement dans le théâtre religieux et le théâtre scolaire. Et comme évoqué dans un article antérieur ${ }^{8}$, les missionnaires, qui sont en fait des colons déguisés, s'inspireront de l'exemple à succès du Moyen Âge, en se servant du théâtre et de certains enseignements de l'Église pour faire passer leur pensée conceptuelle. Les représentations qui se font selon l'idéologie et sous la supervision des missionnaires se donnent dans les chapelles et les paroisses. Il est question d'utiliser le théâtre pour chasser ou évacuer Mammon et implanter Christ dans la brousse africaine.

Ainsi, le but inavoué de ce théâtre est la stigmatisation de la culture de l'homme noir et la diffusion d'une vision dichotomique de ce dernier. Il s'agit de se servir du théâtre comme instrument de propagande pour conditionner et reprogrammer les mentalités. Ceci se traduit au niveau de la caractérisation de certains héros bibliques à savoir Jésus et le diable ${ }^{9}$. Bien plus, on introduit et on met l'accent sur certaines figures ou personnages de la société africaine comme le sorcier, le marabout pour dénoncer notre culture. Ainsi, l'Homme noir était appelé à s'identifier au diable qui symbolise la valeur négative de notre culture. Par conséquent, il devait être obéissant à Dieu pour se faire pardonner et tendre vers la valeur positive qu'incarne l'homme blanc qui est à l'image de Jésus, et qui sert de guide.

En fait, il est question pour les missionnaires, que sont des dramaturges à la soutane, d'utiliser les «enseignements » de l'Église pour culpabiliser l'homme noir, et faire de ce dernier un être docile, soumis et obéissant comme l'exige «Dieu ». Ainsi l'action de ces colons déguisés qui est la première étape dans le processus de la colonisation avait pour but de préparer le terrain. Durant cette période, ils encouragent la création dramatique. Mais les thèmes et les contenus des pièces de cette période témoignent à suffisance 
que cette activité se fait sous le contrôle total de ces derniers. À ce propos, Gilbert Doho affirme :

Sous la direction de ces religieux surgira une pléthore de dramaturges tels que Félix Flaure (Le Diable dans la brousse, 1931); Alfred Tongo Diboundou (Les dix vierges, 1870), Kingue Kwedi (Une famille dans l'attente de Noël, 1910) ; Anonyme (L'Annonce de la naissance de Jésus, 1912) ; Alfred Ndoumbe Moussinga (Un jeune à la recherche d'une surgira) une pléthore de dramaturges tels qu'Alfred Tongo Diboundou (Les dix vierges, conjointe, 1919); Anonyme (Yesus Mongo, 1928); Anonyme (Mfubfub Awula et Ngul Esiki Sosso). Du moment que ces pièces n'inquiètent pas nullement le pouvoir religieux, elles sont représentées dans les séminaires ou dans les Églises lors des fêtes. Elles s'investissent totalement dans la mission impériale de dépossession des Camerounais de leur fond culturel. Car le théâtre religieux est plus qu'un acte de prédication et de justification des conquêtes coloniales.

En plus d'utiliser un théâtre religieux de propagande qui véhiculait une vision dichotomique de l'homme de couleur, ceci dans le but de détruire l'identité culturelle de ce dernier (en lui imposant une nouvelle religion et des noms nouveaux à travers des baptêmes chrétiens), les intentions inavouées des colons s'illustraient également par le pillage des richesses du sol et du sous-sol, la désorganisation de l'ordre social établi, l'attaque de la cosmogonie africaine, l'imposition des langues étrangères et de la culture du colon, l'opposition à certaines valeurs véhiculées par les cultures africaines. Enfin il convient de préciser que pour atteindre ces objectifs, les colonisateurs utilisaient des moyens répressifs dégradants et humiliants.

Les Africains, en l'occurrence les Camerounais, n'arrivent pas aux indépendances lisses et jeunes comme on peut le penser. Car il convient de rappeler que ces peuples épris de liberté ont perdu les repères et les valeurs qui constituaient le socle sur lequel étaient bâties les différentes sociétés traditionnelles. Tel était l'objectif escompté des colons. C'est dire que le théâtre colonial, avec toutes les autres pratiques qui l'accompagnent, a laissé beaucoup de séquelles. Ce qui parait normal dans la mesure où un siècle de colonisation ne saurait s'effacer comme par enchantement dans les mémoires. Ainsi, le théâtre colonial a été pour les colonisés un espace d'aliénation et d'asservissement. C'était un instrument de propagande au service de l'idéologie coloniale qui avait pour but de conditionner, de comprimer et de déprogrammer les mentalités. Et la séquelle la plus grave que la colonisation et ses vecteurs de transmission ont laissée s'observe sur le plan psychologique. Il s'agit du complexe du mythe de l'homme blanc qui est ancré profondément dans la mentalité camerounaise. 
Le théâtre de l'Afrique francophone noire et la théorie postcoloniale : cas du théâtre camerounais des années soixante aux années quatre-vingt

Aussi, lorsque nous arrivons aux indépendances, les dramaturges de la première heure, comme nous l'avons mentionné au préambule de cet article, conscients de leur rôle de portée historique dans ce vaste chantier de reconstruction sociale, vont se proposer, à travers leurs créations dramatiques, de jeter les jalons devant servir de fondation et de frontispice à la reconstruction sociale.

Et s'il y a une œuvre théâtrale de la période postindépendance que tous les spécialistes du théâtre camerounais considèrent comme l'œuvre à succès et la plus représentative de cette période, il s'agit sans aucun doute de Trois Prétendant... un mari de Guillaume Oyônô Mbia. De quoi s'agit-il dans cette pièce emblématique ? Cette œuvre se situe dans le cadre de la société traditionnelle du village de Mvoutessi au Cameroun. Dans la pièce, il s'agit de la décision de la famille d'Atangana concernant le mariage et la dot de leur fille Juliette, l'héroïne de ladite pièce. Dans cette comédie satirique, l'auteur met au jour l'importance de la dot en tant qu'aspect culturel du mariage en Afrique et ses abus. Ce travail permet alors d'explorer et d'examiner certaines pratiques obscures qui entourent la pratique de la dot.

Toutefois, il faut se projeter au-delà des abus que l'auteur met en lumière, pour découvrir les non-dits ou véritables intentions cachées de ce dernier. En effet, il est surtout question pour l'auteur d'inviter ses compatriotes à redécouvrir et s'approprier une valeur de leur culture. Puisque durant la période coloniale, la pulsion créatrice des dramaturges était comprimée, et ces derniers ne traitaient d'aucun sujet portant sur un aspect de leur culture. Ainsi, l'auteur prend conscience des dimensions culturelle, linguistique, didactique et épistémologique de sa création dramatique.

Pour se faire, il mettra en relief la couleur locale de sa région natale dont quelques caractéristiques dans la pièce s'illustrent comme suit :

L'onomastique. Quoiqu'il reflète l'hybridisme issu de l'héritage colonial avec le prénom Juliette de l'héroïne et celui de Matalina, l'auteur donne plus d'importance aux autres principaux personnages, en leur donnant des noms qui trouvent leur origine et une signification dans sa culture, à l'instar de Ndi, Mbia, Atangana, Mbarga, Oko, et Kouma.

Les personnages. Contrairement aux personnages des pièces européennes imposées par les missionnaires, les Camerounais s'identifient facilement aux personnages susnommés, du fait de la proximité qu'ils ont avec ces derniers. Notons aussi, l'introduction d'un personnage important qui est celui du sorcier. En fait, il joue souvent le rôle de trait d'union entre les ancêtres et les vivants. 
La langue. Malgré le fait que la pièce soit rédigée en langue française, l'auteur y a introduit des interjections et des onomatopées qui permettent d'assaisonner la langue. À titre d'exemple : Ekiééé ou Akiéuu pour signifier son étonnement. Ahkah pour manifester son mécontentement. Ahhhh pour signifier sa joie, etc. Notons également l'introduction de certains proverbes et paroles de sagesse pour soutenir la thèse ou le point de vue d'un personnage. Enfin mentionnons les chants ou incantations du sorcier.

Le thème. La pièce traite de la dot. C'est un thème, mieux une valeur importante dans la culture africaine. L'auteur ne milite pas pour l'abandon de la dot, mais il fustige les comportements malsains qui entourent cette pratique.

La cosmogonie. L'introduction du personnage du sorcier est à dessein. Ceci montre que malgré la colonisation, les Africains sont restés fortement attachés à certaines de leurs pratiques cultuelles.

L'espace. La pièce se déroule à Mvoutessi. L'auteur nous invite à découvrir l'espace géographique de sa région natale.

Ainsi Trois prétendants... un mari de Guillaume Oyônô Mbia est avant tout un espace de sensibilisation et de conscientisation contre des attitudes malsaines qui menacent la survie d'une valeur culturelle (la dot) chère aux Africains. Bien plus, cette pièce est un espace de découverte et de valorisation de certaines valeurs découlant du riche patrimoine culturel de la région du Sud-Cameroun.

Le deuxième auteur qui passe pour être l'un des meilleurs de sa génération dans la partie anglophone du Cameroun est Kenjo Jumbam. Et son œuvre The white man of God (qui se traduit en français littéral : «L'homme blanc de Dieu ») nous servira également de support d'analyse. Dans cette œuvre, l'auteur traite du conflit qui oppose les valeurs et idéologies apportées par la colonisation à celles de la culture africaine. En d'autres termes, l'œuvre traite d'un conflit entre le modernisme et le traditionnel au sein d'une famille. D'un côté, nous avons le père et la mère qui sont des fervents catholiques pratiquants ; et d'autre part, nous avons le fils et la grand-mère qui sont plutôt attachés à la tradition.

Il convient de noter qu'ici nous nous situons au lendemain des indépendances. Et cette œuvre, de par son thème, met en lumière l'un des conflits qui sera à l'origine des tiraillements et des ruptures que l'on va observer dans les cellules familiales de cette époque. L'auteur à travers son œuvre peint surtout les conséquences de la colonisation dans les relations humaines. 
Le théâtre de l'Afrique francophone noire et la théorie postcoloniale : cas du théâtre camerounais des années soixante aux années quatre-vingt

Et tout comme son prédécesseur, Kenjo Jumbam va fortement utiliser la couleur locale de sa région natale pour mettre en exergue sa culture, et faire passer le message de son œuvre.

L'onomastique. Les personnages de l'œuvre ont des noms qui sont issus de leur région natale à l'exemple de Tansa, Yaya, Kibarankoh, Juju. En dehors du père et de la mère de Tansa qui sont appelés affectueusement papa et mama, et des deux prêtres blancs.

Les personnages. De par l'appellation de ces personnages, l'auteur fait ressortir deux camps, voir deux idéologies qui s'opposent. Toutefois, les noms issus du répertoire culturel du village natal de l'auteur permettent au lecteur de mieux s'identifier à l'histoire racontée.

Le thème. Le conflit entre le modernisme et le traditionalisme est le thème majeur de l'œuvre. On peut également ajouter l'attachement aux valeurs traditionnelles.

L'espace. L'action se déroule dans le village de Nkar de la tribu Banso dans la région du nord-ouest (anglophone) du Cameroun.

La cosmogonie. L'auteur met en exergue les danses rituelles et guerrières qui sont exécutées par les initiés encore appelés « Juju ». Bien plus, à travers le personnage de Kibarankoh, qui fait souvent le lien entre les vivants et le monde des ancêtres, l'auteur met en lumière les croyances des Banso.

La langue. Bien que l'œuvre soit entièrement rédigée en anglais, l'auteur tout comme son prédécesseur va assaisonner la langue avec des interjections et onomatopées de sa région natale. À titre d'exemple : Vroommmm, Mberuuuu, interjections poussées par les Jujus lors de l'exécution des danses guerrières. Nkaiiiiii, Mafiiiiiii, Eeeeeeeeh, interjections traduisant l'émoi des Jujus à la suite de la provocation de Bigfather.

À travers son œuvre qui traite du conflit entre le modernisme et le traditionalisme, Kenjo Jubam utilise subtilement la couleur locale des Banso pour raconter son histoire. Plus encore, il valorise sa culture. Enfin, cette œuvre est un chant à la résistance aux valeurs imposées par la culture occidentale. Ceci est illustré dans l'œuvre par l'attitude rebelle de Yaya (la grand-mère) et de Tansa (petit-fils), qui malgré les menaces des parents, restent attachés fortement aux valeurs traditionnelles.

Partant de ces deux œuvres emblématiques choisies parmi plusieurs autres de la même nature, il convient de mentionner que les auteurs dramatiques de la période postindépendance étaient tous guidés par un seul courant. En effet, en s'appuyant sur les thèmes, les sujets et motifs, le contenu, la couleur locale et autres traits caractéristiques des œuvres de cette période, il apparaît 
clairement que lesdites œuvres ont pour dénominateur commun : la théorie postcoloniale. Il s'agit en réalité d'une démarche conceptuelle qui s'inspire de la recherche de l'esthétique identitaire.

Toutefois, il serait intéressant d'apprécier l'impact de l'esthétique identitaire prônée par les œuvres théâtrales dans l'imagerie des Africains, en l'occurrence des Camerounais.

\section{Impact de la manifestation de l'esthétique identitaire dans l'imagerie populaire camerounaise}

Pour les auteurs dramatiques de la période postcoloniale, il est question d'utiliser leurs créations dramatiques comme espace de valorisation de la culture africaine, ceci en vue de la reconstruction de l'esthétique identitaire indispensable à l'édification des nouvelles sociétés africaines. Et les valeurs culturelles prônées dans les pièces sont pour ces auteurs les repères (culturel, social, linguistique, etc.) dont les Africains ont besoin pour se lancer dans leur vaste chantier de construction. Aussi l'impact de l'esthétique identitaire prônée par leurs œuvres dans l'imagerie populaire camerounaise pourrait se mesurer comme suit :

- du point de vue idéologique. Le théâtre colonial a été utilisé comme instrument idéologique efficient pour répandre la doctrine coloniale. Aussi, les dramaturges africains, de par les thèmes et les contenus de leurs œuvres en feront de même. Ils vont composer des œuvres qui véhiculent des idéologies s'opposant à celles du théâtre colonial. Ainsi, du point de vue idéologique, les deux formes de théâtre s'opposent. Bien plus, les dramaturges africains font de leurs créations théâtrales, un champ de bataille d'idées, mieux un espace de résistance, de lutte et de reconquête de leur identité culturelle.

- du point de vue psychologique. Comme nous l'avons signalé plus haut, un siècle de pratique coloniale ne se fait pas sans laisser de séquelles, surtout sur le plan psychologique. Le théâtre colonial avait véhiculé des valeurs qui comprimaient et embrigadaient les consciences. Aussi, il était question pour les dramaturges de composer des œuvres qui sont d'abord des exutoires pour leurs compatriotes. Ensuite, ces créations servaient à reprogrammer les mentalités en leur inculquant certaines valeurs culturelles.

- du point de vue linguistique. Ces créations valorisent certains aspects des langues vernaculaires des Africains, par la mise en exergue des chants, des interjections, des onomatopées et de bien d'autres éléments inhérents à la couleur locale. 
Le théâtre de l'Afrique francophone noire et la théorie postcoloniale :

cas du théâtre camerounais des années soixante aux années quatre-vingt

- du point de vue de la culture. Ces œuvres exhument et valorisent certains aspects de la culture tel le mariage, la dot, les rites et rituels, etc.

- du point de vue de la culture individuelle. À travers les lectures plurielles et variées, les lecteurs découvrent l'immensité de leur riche et intarissable patrimoine culturel. Bien plus, ils acquièrent des connaissances nouvelles découlant des univers culturels qui leur étaient jusque-là inconnus.

- du point de vue de la culture théâtrale. Les auteurs dramatiques africains démontrent à travers leurs œuvres leur intention de s'émanciper du corset des œuvres européennes qui leur servaient jusque-là de modèles. On note chez ces derniers un début d'émancipation. Plus encore, certains auteurs à l'instar de Patrice Ndédi Penda (Le Fusils et le Sein est pris); Guillaume Oyônô Mbia (Trois prétendants... un mari) ; Bole Butake (Lake God) pour ne citer que ceux-là, remportent de nombreux prix sur les scènes nationale et internationale, et prouvent par là qu'ils peuvent rivaliser sans complexe avec leurs homologues européens.

\section{Conclusion}

En plus d'être une source permanente d'humiliation et de souffrances (physique et psychologique), les ravages causés par la colonisation sont énormes et parfois inestimables : pillage de certaines richesses : culturelles, forestières et minières ; destruction de l'identité culturelle ; conditionnement et reprogrammation des mentalités ; stigmatisation de la culture de l'homme noir ; et diffusion d'une vision dichotomique de ce dernier, etc. Et à l'accession aux indépendances, il se pose une préoccupation, celle de savoir comment s'évertuer dans la grande entreprise de reconstruction sociale sans repères culturels ? Apportant donc leur contribution intellectuelle à ce vaste chantier national, les dramaturges camerounais de la première heure vont se lancer dans une création dramatique exclusivement orientée vers la recherche de l'esthétique identitaire. Ainsi, dans le présent article, il était question de s'appuyer sur la théorie postcoloniale pour démontrer que les créations dramatiques de l'Afrique francophone noire postindépendance, en l'occurrence celles du Cameroun, sont de véritables espaces de résistance, de lutte et de reconquête de l'identité culturelle, et partant de libertés individuelle et collective. Ce faisant, l'atteinte de cet objectif a permis de déboucher sur quelques résultats : premièrement, c'est par un théâtre (guidé par la théorie postcoloniale) que les auteurs dramatiques de la période postindépendance ont corrigé le mal fait par le théâtre colonial. Deuxièmement, le théâtre postcolonial est un espace de lutte, de résistance et de reconquête de culture et de libertés individuelle 
et collective. Et enfin, le théâtre postcolonial était essentiellement orienté sur la recherche de l'esthétique identitaire. Ce faisant, cette forme de théâtre était un champ de bataille idéologique.

\section{Notes}

1. Quoique le Cameroun n'ait jamais reçu le statut officiel de " pays colonisé », mais plutôt celui de " pays sous-tutelle ", il convient tout de même de souligner que l'idéologie du colon était appliquée de la même manière sur les territoires qu'il occupait.

2. Théoriciens allemands du théâtre ayant base ses recherches sur le conditionnement pavlovien.

3. Citation tirée de Google historical page.

4. Kipling est l'un des architectes de la doctrine coloniale. C'est ce dernier qui, pour justifier le fait colonial, parlera du fardeau de l'homme blanc ou de la mission civilisatrice.

5. Système de gouvernance administré dans les colonies françaises. Dans ce système, la France gère ses colonies sans partage.

6. Système de gouvernance administrée dans les colonies anglaises. Contrairement aux Français, les Anglais associent les Africains à l'administration de leurs pays.

7. Nées au cœur même de l'action coloniale et de son entreprise de formation, les expressions dramatiques africaines sont le produit d'une hybridation maîtrisée par les maîtres d'école et les pères blancs. L'histoire de l'École William-Ponty qui cristallise l'origine du théâtre africain francophone est tout à fait emblématique à ce sujet. Charles Béart, qui dans les années trente lança ce projet de théâtre scolaire dans la prestigieuse École d'administration de Gorée n'a cessé de défendre le théâtre africain comme la plus belle expression de la culture franco-africaine.

8. Le Théâtre religieux au Cameroun.

9. Ces personnages sont respectivement vêtus de blanc et de noir. Le blanc symbolisant ici la vertu, la pureté ; et le noir, la nuit, voire le mal et les ténèbres. Pour renforcer ces valeurs, on utilisait les costumes et le maquillage. 